\title{
Endodontic management of horizontal root fractures in maxillary central incisors
}

\section{Kothandaraman Sathyanarayanan}

Department of Conservative Dentistry and Endodontics, Sathyabama University Dental College and Hospital, Chennai, Tamil Nadu, India

\author{
Address for correspondence: \\ Dr. Kothandaraman Sathyanarayanan, \\ Department of Conservative Dentistry \\ and Endodontics, Sathyabama \\ University Dental College and Hospital, \\ Jeppiar Nagar, OMR Road, \\ Chennai - 119, Tamil Nadu, India. \\ E-mail: drsathya_ods@yahoo.com
}

\begin{abstract}
Root fracture implies fracture of cementum, dentin, and pulp. These injuries are relatively infrequent as they constitute $<3 \%$ of all dental injuries. When a root fracture occurs horizontally, the coronal segment may or may not be displaced. This article illustrates two varied treatment options for horizontal root fractures in maxillary central incisors. In the first case, endodontic treatment was performed using a mineral trioxide aggregate (MTA)-based sealer. In the second case, repositioning and splinting of the teeth allowed revascularization and preservation of teeth vitality. A 12-month follow-up period was reported for the two cases.
\end{abstract}

Key words

Dental trauma, endodontic treatment, pulp healing, root fracture

\section{INTRODUCTION}

Root fracture results after the impingement of high force upon the root. Frontal forces effect compression zones labially and lingually or palatally and separate the root into a coronal and an apical fragment. This has detrimental consequences for the cementum, dentin, pulp, and periodontium. ${ }^{[1]}$

Compared to other dental traumas, root fractures are relatively uncommon. The frequency of root fractures in permanent teeth is only $0.5-7 \%$, and, in deciduous teeth, it is only $2-4 \% .{ }^{[2]}$ The classification of horizontal root fractures is based on the location of the fracture line (apical third, middle third, cervical third of the root) and on the degree of dislocation of the coronal fragment. The prognosis of the tooth concerned is also influenced by other factors, such as the patient's age, stage of root growth, mobility of the coronal fragment, and diastasis of the fragments. ${ }^{[2]}$ Fractures in the middle third of the root are the most common. ${ }^{[3]}$

\begin{tabular}{|l|l|}
\hline \multicolumn{2}{|c|}{ Access this article online } \\
\hline Quick Response Code: & Website: \\
\hline & www.ejgd.org \\
\cline { 2 - 3 } & \\
\hline
\end{tabular}

Mineral trioxide aggregate (MTA) is a biocompatible material with numerous interesting clinical applications in endodontics. The material appears to be an improvement over other materials for some endodontic procedures that involve root repair and bone healing. ${ }^{[4]}$

The purpose of this article is to describe two varied treatment options for horizontal root fractures in maxillary central incisors.

In the first case, we performed root canal treatment for the coronal segment, thereby preserving the vital pulp tissue of the apical segment. In the second case, immediate splinting of the fracture fragments was done to preserve the vitality of the pulp tissue and to promote pulp healing.

\section{CASE REPORTS}

\section{Case 1}

A 24-year-old male patient reported with an impact injury of his upper anterior teeth 6 years back, which resulted in discolouration of his maxillary right central incisor. The clinical examination revealed no mobility and discomfort during percussion of his maxillary right central incisor. The tooth did not respond to electric and thermal pulp tests. Radiographic examination revealed horizontal root fracture at the middle third of maxillary right central incisor with interposition of calcified tissue (callus formation). The root canal was narrowed and showed 
signs of obliteration when compared to the root canal space of maxillary left central incisor [Figure 1].

Conventional root canal treatment of the coronal segment was performed. After access cavity preparation and working length determination, intra canal calcium hydroxide was placed and was renewed every 2 weeks for 1 month.

After chemo-mechanical preparation of the coronal segment, the master cone radiograph was taken [Figure 2] and it was obturated with gutta-percha and MTA-based root canal sealer (MTA Fillapex, Angelus) [Figure 3]. One-year postoperative radiograph revealed healing with calcified tissue [Figure 4].

In the first case, traumatic injury had occurred 6 years earlier. Healing by hard tissue formation between the fracture segments along with calcification of the root canals in the coronal segments was present. After the root canal treatment of the coronal segment with MTA-based sealer, the healing process was enhanced without any signs and symptoms.

\section{Case 2}

A 21-year-old female patient reported an impact injury of her upper anterior teeth $1 \mathrm{~h}$ earlier. The clinical examination revealed grade III mobility of her maxillary right and left central incisors, and it was palatally extruded. Radiographic examination revealed horizontal root fracture at the middle third of the maxillary right and left central incisors [Figure 5]. Immediate repositioning and stabilization of the fractured fragments was done with composite wire splint for 2-4 weeks, as recommended by Flores et al. [Figure 6]. ${ }^{[5]}$

The patient was then on a monthly recall. At 6-months recall, the clinical examination revealed no mobility or discomfort during percussion of her maxillary right and left central incisors. The pulp responded normally to cold and electric pulp tests. No treatment was indicated, as the pulpal response was normal to vitality tests.

Proper repositioning of the fractured fragments appeared to enhance the likelihood of both pulp healing and hard tissue repair. It is likely that, in many cases, the pulp in the coronal segment becomes necrotic after the injury; however, because of a very large apical opening in the coronal segment, revascularization is possible if the segments are well re-approximated. At 12-months recall, the tooth was asymptomatic and the pulpal response was normal [Figure 7].

\section{DISCUSSION}

Root fracture is one of the consequences of dental trauma. The treatment principles for horizontally fractured teeth involve maintaining pulp vitality by immobilizing the coronal segment. The first step for management of horizontal root-fracture cases is to reposition the tooth and confirm its position radiographically. ${ }^{[2]}$

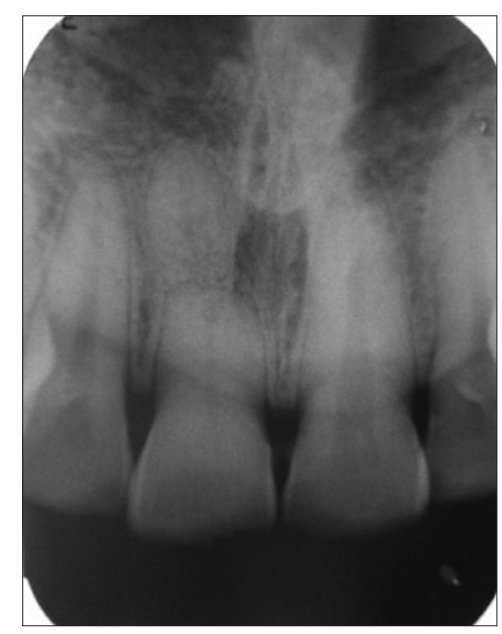

Figure 1: Pre-operative radiograph

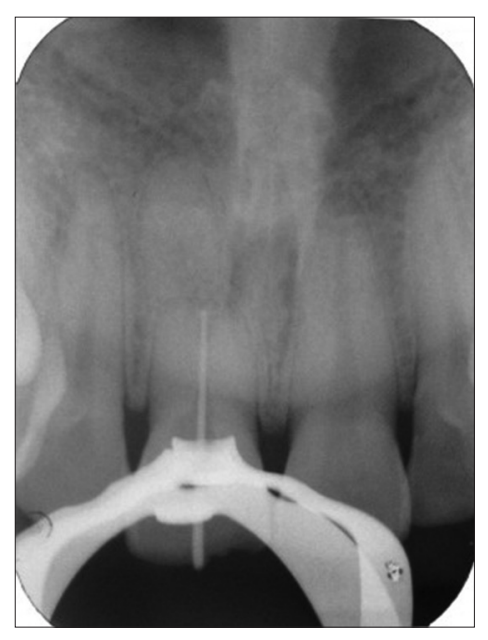

Figure 2: Master cone radiograph

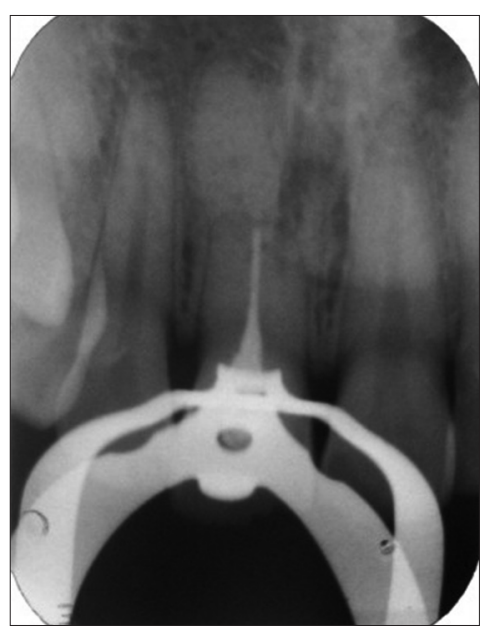

Figure 3: Obturation radiograph 


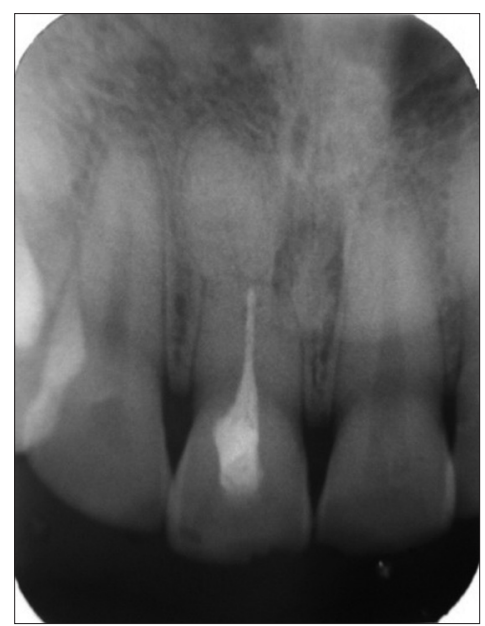

Figure 4: One year post-operative radiograph

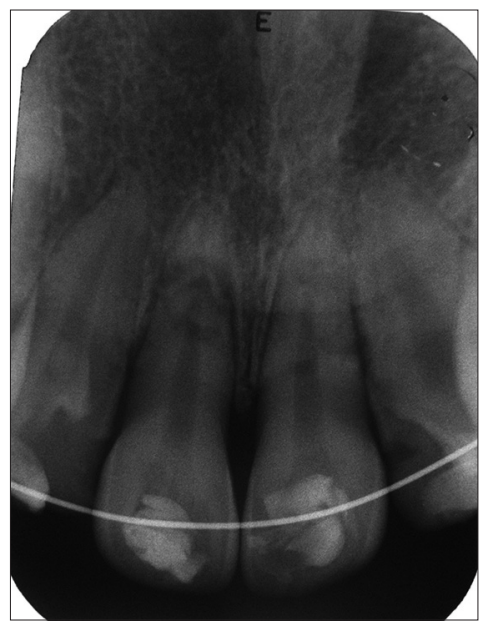

Figure 6: Fractured segments repositioned

The histological reactions at the fracture line are categorized into four types: (I) Interposition of calcified tissue (callus formation); (II) interposition of connective tissue, which is characterized by peripheral rounding of the fracture's ends; (III) interposition of bone and connective tissue, radiologically characterized by the clear separation of the two fragments; and (IV) interposition of granulation tissue, caused by an infected or necrotic pulp. ${ }^{[2]}$ Type I is found most commonly in root-fractured teeth in which the coronal fragment is not or only slightly dislocated. Type II often results after lateral dislocation or extrusion of the coronal fragment. If the trauma occurs before growth of the alveolar process is complete, the coronal fragment continues to erupt, but the apical fragment remains in its pre-trauma position. As a result, bone and connective tissue grow between the two fragments (type III). In type IV, infected or necrotic pulpal tissue causes an inflammatory reaction in the fracture line. ${ }^{[2]}$

The patient's age at the time of injury is considered as one of the most important factors in pulpal healing after root fracture. Andreasen et al. ${ }^{[6]}$ studied the influence of "pre-injury and injury factors" on the healing of

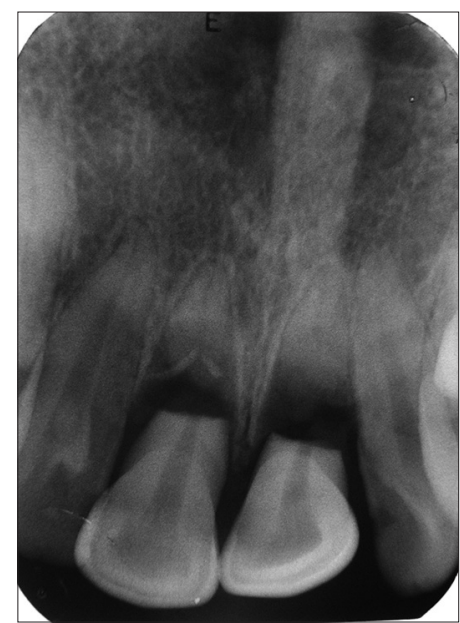

Figure 5: Pre-operative radiograph

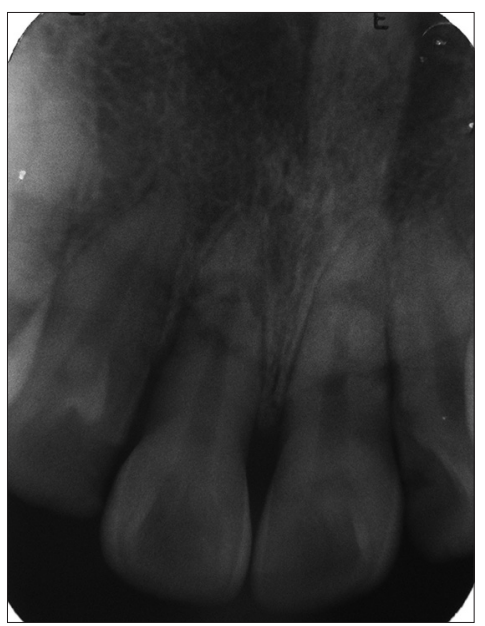

Figure 7: One year post-operative radiograph

400 intra-alveolar root fractures. Those authors found that the age of the patients, the stage of root growth, mobility of the coronal fragment, and dislocation of the coronal fragment exerted the greatest influence on healing at the fracture line and on the occurrence of pulpal necrosis.

Calcium hydroxide dressing disinfect the root canal and maintain the root canal of high $\mathrm{pH}$ value, an environment suitable for hard tissue formation and MTA setting. ${ }^{[7]}$ The guidelines by the International Association of Dental Traumatology (IADT) ${ }^{[5]}$ recommend endodontic treatment only after pulp necrosis, and not as a prophylactic intervention. Nevertheless, root-fractured teeth in children and adolescents or root-fractured teeth with a minimum dislocation of the coronal fragment, independent of the patient's age, should not be prophylactically endodontically treated; rather, pulp healing should be carefully observed for a minimum of 1 year..$^{[5]}$ For the second case, proper repositioning of the fractured segments appeared to enhance the pulp healing and hard tissue repair. Root-fractured teeth often possess a vital apical fragment, even when the coronal fragment 
is necrotic. Therefore, only the coronal fragment should be endodontically treated. ${ }^{[8]}$ The coronal fragment was endodontically treated for the first case.

\section{CONCLUSION}

This article illustrates two case reports with varied treatment options for the management of horizontal root fractures. Availability of biocompatible materials like MTA and proper understanding of the biological concepts of root fracture helps in better prognosis of root fractures.

\section{REFERENCES}

1. Welbury R, Kinirons M, Day P, Humphreys K, Gregg TA. Outcomes for root-fractured permanent incisors: A retrospective study. Pediatr Dent 2002;24:98-102.

2. Andreasen JO, Andreasen FM, Andersson L, editors. Textbook and Color Atlas of Traumatic Injuries to The Teeth. Munksgaard, Kopenhagen; 2007. p. 337-71.

3. Andreasen FM, Andreasen JO, Bayer T. Prognosis of root-fractured permanent incisors-prediction of healing modalities. Endod Dent
Traumatol 1989;5:11-22.

4. Bramente CM, Menezes R, Moraes IG, Bernardinelli N, Garcia RB, Letra A. Use of MTA and intracanal post reinforcement in a horizontally fractured tooth: A case report. Dent Traumatol 2006;22:275-8.

5. Flores MT, Andersson L, Andreasen JO, Bakland LK, Malmgren B, Barnett F, et al. Guidelines for the management of traumatic dental injuries. I. Fractures and luxations of permanent teeth. Dent Traumatol 2007;23:66-71.

6. Andreasen JO, Andreasen FM, Mejàre I, Cvek M. Healing of 400 intra-alveolar root-fractures. 1. Effect of pre-injury and injury factors such as sex, age, stage of root development, fracture type, location of fracture and severity of dislocation. Dent Traumatol 2004;20:192-202.

7. Lee YL, Lee BS, Lin FH, Yun Lin A, Lan WH, Lin CP. Effects of physiological environments on the hydration behaviour of mineral trioxide aggregate. Biomaterials 2004;25:787-93.

8. Cvek M, Mejàre I, Andreasen JO. Conservative endodontic treatment of teeth fractured in the middle or apical part of the root. Dent Traumatol 2004;20:261-9.

How to cite this article: Sathyanarayanan K. Endodontic management of horizontal root fractures in maxillary central incisors. Eur $\mathrm{J}$ Gen Dent 2014;3:75-8.

Source of Support: Nil, Conflict of Interest: None declared. 